\title{
Potential of Baeyer-Villiger monooxygenases as an enzyme for polyethylene decomposition
}

\author{
Ye Rin Yoon ${ }^{1} \cdot$ Yu-Sin Jang ${ }^{1}$ \\ 폴리에틸렌 분해를 위한 효소로써 Baeyer-Villiger monooxygenases의 \\ 잠재력
}

윤예 린 ${ }^{1}$ 장유신 ${ }^{1}$

Received: 3 November 2021 / Accepted: 16 November 2021 / Published Online: 31 December 2021

(C) The Korean Society for Applied Biological Chemistry 2021

\begin{abstract}
Polyethylene is widely used as an agricultural film, but eco-friendly technology is lacking for its decomposition. Thus, recently, much attention has been paid to develop a technology for biological polyethylene decomposition. It has been expected that several oxidation steps will be required in the biological degradation of polyethylene. First, secondary alcohol is formed on the polyethylene chain, and then the alcohol is oxidized to a carbonyl group. In the subsequent process, the carbonyl group is converted to an ester by Baeyer-Villiger monooxygenase (BVMO), and this ester bond is expected to be cleaved by lipase and esterase in the final step. In this work, we reviewed BVMO as one of the promising enzymes for polyethylene decomposition, in terms of its reaction mechanism, classification, and engineering. In addition, we also give a brief perspective on polyethylene decomposition using BVMO.
\end{abstract}

Keywords Baeyer-Villiger monooxygenases · Enzyme engineering - Mechanism · Polyethylene

Yu-Sin Jang $(\bowtie)$

E-mail: jangys@gnu.ac.kr

${ }^{1}$ Division of Applied Life Science (BK21), Department of Applied Life Chemistry, Institute of Agriculture \& Life Science (IALS), Gyeongsang National University (GNU), Jinju, Republic of Korea

This is an Open Access article distributed under the terms of the Creative Commons Attribution Non-Commercial License (http://creativecommons. org/licenses/by-nc/3.0/) which permits unrestricted non-commercial use, distribution, and reproduction in any medium, provided the original work is properly cited.
서 론

플라스틱은 밀도가 낮아 가공성이 좋고 대량생산이 가능하기 때 문에 산업과 일상 속에서 다방면으로 이용되면서 세계 플라스 틱 생산량이 급속도로 증가해 왔다[1]. 연간 생산되는 플라스틱 은 3억 5,000만에서 4억 톤이며, 재활용 되지 못한 폐플라스틱 은 대부분 매립되거나 방치되고 있다[1,2]. 심지어 매년 바다로 유입되는 플라스틱만으로도 500 만에서 1,300 만톤에 달하고 있 다[3]. 이는 자연 생태계 뿐 아니라 인간에게도 부정적인 영향 을 초래하는 것으로 잘 알려져 있기 때문에 폐플라스틱 처리를 두고 전세계가 대책 마련을 위한 노력을 기울이고 있다.

한편, 전체 플라스틱 중 생산량 1 위를 차지하는 폴리에틸렌 (PE, polyethylene)은 전세계적으로 매해 1억 톤 이상 생산된다 [4]. $\mathrm{PE}$ 는 에틸렌 $\left(\mathrm{C}_{2} \mathrm{H}_{4}\right)$ 이 반복적으로 결합된 중합체로 기다란 탄화수소사슬을 이루고 있다. $\mathrm{PE}$ 는 밀도에 따라서 저밀도 폴리 에틸렌(LDPE, Low Density Polyethylene)과 고밀도 폴리에틸렌 (HDPE, High Density Polyethylene)으로 분류된다[5]. LDPE는 결정화 온도가 낮고 유연성이 우수하여 식품 저장 용도 이외에 도 각종 비닐, 코팅제, 농업용필름의 제조에 사용되며, $\mathrm{HDPE}$ 는 결정화 온도가 높고 단단하여 각종 파이프나 샴푸, 비누, 세제 보관용 용기 제조에 사용된다[1]. $\mathrm{PE}$ 의 큰 특징 중 하나는 뛰 어난 내화학성인데 이는 PE가 탄소와 수소로만 이루어진 탄화 수소 사슬의 구조를 가지고 있어 반응성이 매우 작기 때문이다 [1,5]. 이와 같은 구조적 특징으로 인해 $\mathrm{PE}$ 는 강한 소수성을 띄 고 있을 뿐만 아니라 분자량이 크기 때문에 일반적으로 생명체 가 가진 효소의 접근이 매우 어려운 것으로 알려져 있다[6-8]. 이로 인하여 $\mathrm{PE}$ 의 생분해가 비교적 어려운 것으로 알려져 있 으며, 분해되는 데 걸리는 시간은 $\mathrm{HDPE}$ 의 경우 약 100 년, LDPE의 경우 최소 500년 이상으로 알려져 있다[9]. 이는 다른 
환경 위해요인들과 더불어 토양에 오랫동안 잔류가 가능함을 나 타낸다[10-12].

최근, $\mathrm{PE}$ 분해에 대한 관심이 높아지면서 이들을 분해하는 미생물이 자연계에 존재한다는 보고들이 증가하고 있다 $[1,5,13]$. 하지만, 아직까지 $\mathrm{PE}$ 분해에 직접적으로 관여하는 효소들이 무 엇인지는 정확히 밝혀져 있지는 않다. 다만, $\mathrm{PE}$ 의 구조 및 자 연으로부터 분리한 미생물들의 특징을 기반으로 $\mathrm{PE}$ 분해 예상 경로가 몇 가지 제안되어 있다[13,14]. 대표적인 예상 경로 중 하나는 $n$-alkane의 분해에서 아이디어를 얻은 것으로써, 비교적 긴 사슬의 alkane이 Penicillium, Bacillus, Pseudomonas, Rhodococcus [15]속의 미생물이 가진 효소 작용에 의해 분해되는 것으로 추 정하고 있다[16]. 이와 같은 긴 사슬 alkane 분해 미생물들은 $\mathrm{PE}$ 분해와 관련이 있다고 보고된 미생물과 일치하는 경우가 많 기 때문에 이 가설은 상당히 높은 신뢰를 얻고 있다 $[4,5,7,17,18]$. 이와 같은 $\mathrm{PE}$ 의 생물학적 분해 경로에서는 $\mathrm{PE}$ 의 subterminal oxidation 과정부터 시작할 것으로 예측하고 있다[19](Fig. 1). Alkane의 subterminal oxidation 반응은 alkane monooxygenase 에 의해 매개되며, 이 반응으로 부터 2차 알코올이 생성된다 (Fig. 1). 다음 반응 단계에서 2차 알코올은 alcohol dehydrogenase 에 의해 케톤으로 산화된다(Fig. 1). 이후 케톤은 BaeyerVilliger monooxygenase (BVMO)에 의해 에스터로 전환되고, 이 에스터 결합은 최종 단계에서 lipase 및 esterase에 의해 분 해된다(Fig. 1). 이렇게 생성된 지방산은 $\beta$-oxidation cycle로 들 어가서 대사 될 것으로 예측되고 있다. 따라서, 본 고에서는 $\mathrm{PE}$ 분해 예상 경로에서 중요 역할을 할 것으로 예상되는 $\mathrm{BVMO}$
를 소개하고, 이 효소의 반응메커니즘, 분류, 효소 공학을 통한 개량과 관련된 최신 연구들을 리뷰하고자 한다. 이와 더불어 $\mathrm{PE}$ 분해 공정 개발에 있어서 $\mathrm{BVMO}$ 의 이용 가능성을 간략히 전 망하였다.

\section{BVMO 효소의 반웅 메커니즘}

$\mathrm{BVMO}$ 는 ketone 또는 cyclic ketone의 carbonyl 작용기 다음에 산소 원자를 삽입하여 ester 또는 lactone으로 전환하는 BaeyerVilliger (BV) oxidation 반응을 촉매하는 flavoenzymes으로 알 려져 있다[20]. 이 효소는 보결분자단으로써 flavin adenine dinucleotide (FAD)와 결합되어 있으며 환원제 역할을 하는 $\mathrm{NAD}(\mathrm{P}) \mathrm{H}$ 를 보조인자로 필요로 한다(Fig. 2). 이 두 조효소는 $\mathrm{BVMO}$ 에 의한 기질(케톤 그룹을 가진 alkane 또는 $\mathrm{PE}$ )의 산화 반응에서 친핵성 공격을 위한 nucleophile의 형성에 매우 중요 한 역할을 한다.

단계별 반응 메커니즘 측면에서, 첫번째와 두번째 반응은 $\mathrm{BVMO}$ 효소의 활성화 과정으로 이야기할 수 있다. 첫번째 단 계에서는 $\mathrm{NAD}(\mathrm{P}) \mathrm{H}$ 가 $\mathrm{BVMO}$ 와 반응하여 효소와 공유 결합하 고 있는 보결분자단 flavin을 환원시켜 flavin semiquinone을 생 성하는 것으로 알려져 있다[21,22](Fig. 2). 다음 단계 반응에서 산소 한 분자가 참여하게 되는데, 이 산소 분자는 반응의 첫번 째 단계에서 만들어진 flavin semiquinone에 의해서 활성화되는 것으로 알려져 있다(Fig. 2). 이 두번째 반응의 산물로써 기질 을 친핵 공격하기 위한 nucleophile인 flavin $\mathrm{C} 4 \alpha$-peroxide 중간 체가 생성된다(Fig. 2). 이와 같은 nucleophile인 flavin $\mathrm{C} 4 \alpha-$

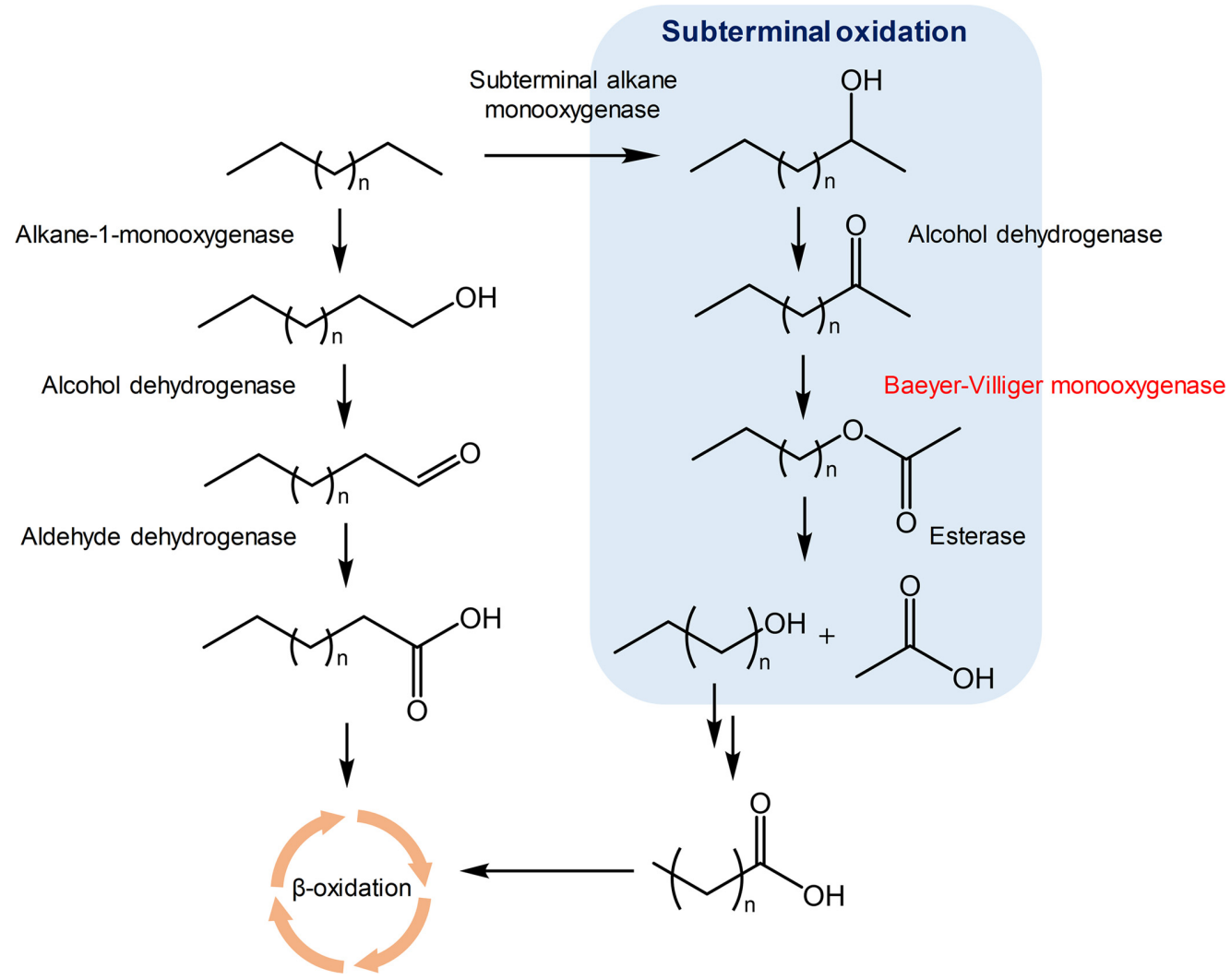

Fig. 1 Predicted pathway for decomposition of long-chain alkane or polyethylene [16] 


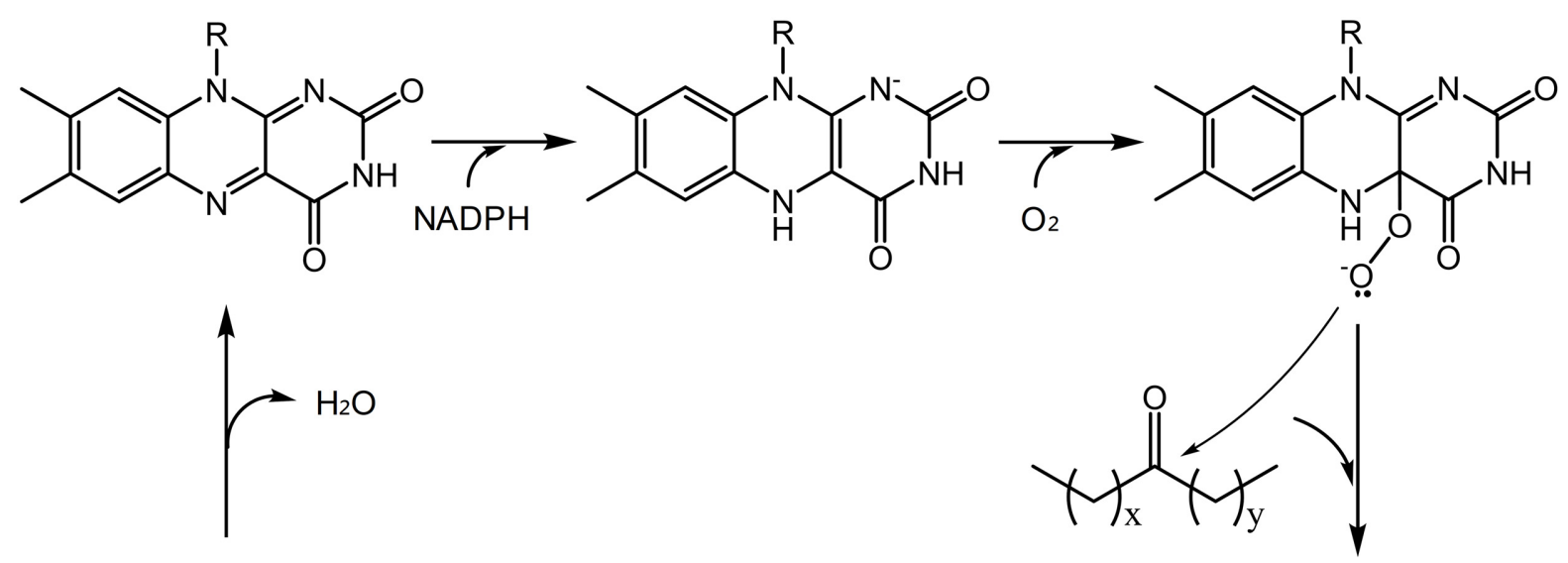<smiles>[Y]C1C2=NC(=O)NC(=O)C2(OOC(C)(C)C)Nc2cc(C)c(C)cc2N1[R]</smiles>

Fig. 2 Schematic presentation of the reaction mechanism of the Baeyer-Villiger monooxygenases

Table 1 Classification of BVMOs [24]

\begin{tabular}{cccccc}
\hline \hline BVMO type & Prosthetic group & Cofactor & $\begin{array}{c}\text { Flavoprotein } \\
\text { subclass }\end{array}$ & $\begin{array}{c}\text { Number of polypeptide } \\
\text { components }\end{array}$ & Sources \\
\hline I & FAD & NADPH & B & 1 & Thermobifida fusca \\
II & FMN (substrate) & NADH & C & 2 & Pseudomonas putida ATCC 17453 \\
O & FAD & NADPH & A & 1 & Streptomyces argillaceus ATCC 12956 \\
\hline
\end{tabular}

peroxide 중간체 형성 과정에서는 $\mathrm{BVMO}$ 효소의 active site에 있는 arginine 잔기가 매우 중요한 역할을 하는 것으로 알려져 있다[23]. BVMO 반응의 세 번째 단계에서는 nucleophile인 flavin C4a-peroxide 중간체가 기질의 케톤 그룹 탄소원자를 친 핵 공격하는 것으로 알려 있다(Fig. 3). 따라서, 이 반응의 결과 물로써 효소의 active site의 flavin $\mathrm{C} 4 \alpha$-peroxide와 기질이 결합 된 사면체 Criegee 중간체가 형성된다(Fig. 2). 최종 단계인 네 번째 반응에서 이 중간체는 재배열을 통하여 반응산물로써 ester 로 전환된다. 이 모든 반응 단계에서 환원 및 hydroxyl화된 flavin은 탈수 반응을 통하여 복원되어 다음 반응에 참여하는 것 으로 알려져 있다[24,25](Fig. 2).

\section{BVMO 효소의 분류}

$\mathrm{BVMO}$ 는 최근 $\mathrm{PE}$ 분해 과정의 주요 효소로 부각되어 많은 주 목을 받고 있는 효소이기도 하지만, 그 이전에는 주로 나일론 원료인 caprolactone의 상온 생산을 위한 공정개발에 있어서 주 목 받는 효소 중 하나였다[26]. 이와 같은 산업적 중요성으로 많은 $\mathrm{BVMO}$ 들이 원핵생물 뿐만 아니라 진핵생물에서도 연구되 어 보고되어 있으며, 그 기질 다양성 또한 매우 폭 넓은 것으
로 알려져 있다. 일반적인 $\mathrm{BVMO}$ 의 분류는 효소에 공유결합 되어 있는 보결분자단의 종류, flavoprotein으로써의 subclass, 반 응에 관여하는 보조인자의 종류 등에 따라 분류되고 있다. 이 들의 특징에 따라 type I, II, O로 분류되고 있다(Table 1).

\section{Type I BVMO}

Type I BVMO는 보결분자단으로 $\mathrm{FAD}$ 를 가지며, $\mathrm{NADPH}$ 를 보조인자로 가지는 class B flavoprotein monooxygenase에 속 한다[20]. 또한, Type I BVMO는 단일 폴리펩타이드로 구성되 어 있는 것으로 알려져 있다(Table 1). Type I BVMO에서 특 징적으로 관찰되는 주요 motif는 $\mathrm{FXGXXXHXXXW[P/D]}$ 와

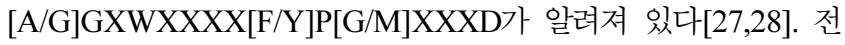
자인 FXGXXXHXXXW[P/D] motif는 type I BVMO의 fingerprinting motif로 불릴 정도로 동일 type에서 매우 높은 보 존성을 나타내는 것으로 알려져 있다[27-29]. Fingerprinting motif는 효소활성에 직접 관여하지는 않지만 FAD 및 $\mathrm{NADPH}$ 결합도메인 사이를 연결함으로써 촉매작용 동안 변화하는 효소 형태의 안정성 유지에 기여하는 것으로 알려져 있다[27,30]. 후 자인 $[\mathrm{A} / \mathrm{G}] \mathrm{GXWXXXX[F/Y]P[G/M]XXXD} \mathrm{motif는} \mathrm{active} \mathrm{site}$ 
에 위치하는 것으로 알려져 있으며, 보조인자인 $\mathrm{FAD}$ 와 $\mathrm{NADPH}$ 가 각각 결합하는 자리인 Rossmann 폴드 $(\mathrm{GxGxx}[\mathrm{G} / \mathrm{A}])$ 들 사이 에 위치하는 것으로 알려져 있다[27,28]. Active site에서 이 motif의 aspartate (D) 잔기는 조효소와 직접적인 상호작용을 하 는 것으로 알려져 있다[30].

Type I BVMO의 대표적인 예로는 세균 유래의 Thermobifida fusca의 phenylacetone monooxygenase (PAMO)[27], Rhodococcus sp. HI-31의 cyclohexanone monooxygenase (CHMO)[29], Rhodococcus rhodochrous 의 steroid monooxygenase (STMO) [25] 등이 알려져 있다. 또한, 곰팡이 유래의 type I BVMO로 는 Aspergillus flavus 의 $\mathrm{BVMO}_{\mathrm{AFL} 838}$ 가 잘 알려져 있다[31].

\section{Type II BVMO}

Type II BVMO는 type I BVMO와 달리 FMN과 NADH를 보조인자로 사용하는 것이 특징이다[26]. 또한, 두 개의 폴리펩 타이드로 구성되어 있는 것도 type II $\mathrm{BVMO}$ 의 주요 특징이다 [26]. 이상의 특징을 가지면서 class C flavoprotein monooxygenases로 분류되면 type II BVMO로 분류한다[32,33]. 이미 언 급한 것과 같이 type II $\mathrm{BVMO}$ 의 경우 폴리펩타이드가 2개로 구성되어 있으며, 첫번째 폴리펩타이드는 보조인자로 $\mathrm{NADH}$ 를 사용하여 $\mathrm{FMN}$ 을 환원시키는 역할을 하는 것으로 알려져 있다 [26]. 환원된 $\mathrm{FMN}$ 은 자유 확산을 통하여 나머지 또 다른 폴리 펩타이드로 이동하여 산소 활성화 과정에 이용됨으로써 결국 nucleophile 형성에 기여하는 것으로 알려져 있다[34].

Type II BVMO의 대표적인 예로는 장뇌(camphor, $\mathrm{C}_{10} \mathrm{H}_{16} \mathrm{O}$ ) 대사에 관여하는 Pseudomonas putida ATCC 17453의 diketocamphane monooxygenase (DKCMO)가 알려져 있다[35]. 상기 P. putida의 경우는 두개의 서로 다른 $\mathrm{DKCMO}$ 를 가지는 것으로 알려져 있으며, 각각 2,5- 및 3,6-diketocamphane monooxygenases (2,5-DKCMO 및 3,6-DKCMO)로 보고되어 있다[26]. 두 효소는 라세미 혼합물인 camphor의 이화작용 과 정에 각각 참여하며, $2,5-\mathrm{DKCMO}$ 와 $3,6-\mathrm{DKCMO}$ 는 $2,5-$ diketocamphene과 3,6-diketocamphene의 산화 반응을 각각 특이 적으로 촉매하는 것으로 알려져 있다[36].

\section{Type O BVMO}

Type O BVMO는 앞서 언급한 type I BVMO 및 type II $\mathrm{BVMO}$ 와 다소 동떨어진 특징을 보여주고 있다. Type $\mathrm{O}$ $\mathrm{BVMO}$ 에서는 이미 앞서 언급한 type I $\mathrm{BVMO}$ 에서 발견된 motif가 전혀 발견되지 않을 뿐만 아니라, type I BVMO 및 type II BVMO와 비교에서 구조적 유사성 또한 발견되지 않은 것으로 알려져 있다[24]. 대표적인 type O BVMO는 Streptomyces argillaceus ATCC 12956의 MtmOIV이다[37]. Type O BVMO 인 MtmOIV는 항암제로 사용되는 polyketide인 mithramycin 생 합성 과정에서 산화반응을 촉매하는 것으로 알려져 있다[26]. Type O BVMO인 MtmOIV는 $\mathrm{FAD}$ 를 보결분자단으로, $\mathrm{NADPH}$ 를 보조인자로 사용하며, 이 효소는 class A flavoprotein monooxygenase에 속한다[33].

Type O BVMO의 특이점은 MtmOIV의 경우와 같이 단일 $\mathrm{BV}$ 반응을 촉매 할 수 있지만, 대부분 $\mathrm{BV}$ oxidation 외의 다른 반응들을 촉매하는 다기능 효소라는 점이다[38,39] 예를 들자면, 어떠한 $\mathrm{BVMO}$ 는 산소 삽입, 가수분해, 탈카복실화 세 단계의 cascade 반응을 매개한다고 알려져 있다[39-41]. 따라서 비슷한 기능을 하는 type O BVMO별로 서열의 유사성이 높을 뿐 $\mathrm{MtmOIV}$ 와 다른 type $\mathrm{O} \mathrm{BVMO}$ 들과는 유사한 서열이 존재하 지 않을 수 있다[40].

\section{효소공학을 이용한 $\mathrm{BVMO}$ 의 개량}

$\mathrm{BVMO}$ 는 최근 $\mathrm{PE}$ 분해 과정에 필요한 효소로써 주목 받고 있 을 뿐만 아니라 이미 산업적으로도 금속 촉매 화학합성에서 조 절하기 어려운 반응을 대체하기 위한 생촉매로써 주목 받고 있 다. 그럼에도 불구하고, 자연계에 존재하는 야생형 $\mathrm{BVMO}$ 를 위 와 같은 공정에 적용하기 위해서는 개선이 필요한 점도 존재한 다. 산업용 효소로 활용하기 위해 일반적으로 요구되는 효소의 안정성 향상을 제외하고도 $\mathrm{BVMO}$ 의 보조인자 요구성과 관련된 개선이 필요하다는 점에서는 이견이 없다. Type I BVMO 및 type $\mathrm{O} \mathrm{BVMO}$ 의 보조인자로 사용되는 $\mathrm{NADPH}$ 는 $\mathrm{NADH}$ 에 비해 10 배 이상 비싼 것으로 알려져 있으며, $\mathrm{NADP}^{+}$의 재생성 (재환원성) 또한 $\mathrm{NAD}^{+}$에 비해 낮은 것으로 알려져 있다[42]. 이 로 인하여 야생형의 type I BVMO 및 type $\mathrm{O} \mathrm{BVMO}$ 를 이용 한 공정은 경제성이 매우 떨어져 실제 공정에서 사용하기에는 어려움이 있다. 이와 같은 이유들 때문에 $\mathrm{BVMO}$ 의 보조인자인 $\mathrm{NADPH}$ 의 의존성을 낮추기 위한 연구들이 수행된 바 있다.

예를 들면, 효소공학을 통하여 $\mathrm{NADPH}$ 의존형 $\mathrm{BVMO}$ 를 $\mathrm{NADH}$ 의존형으로 개량한 것이 대표적인 사례이다[43]. 이를 위해 Acinetobacter sp. NCIMB 9871의 cyclohexanone monooxygenase가 이용되었으며, 이 야생형 효소는 NADPH를 보조인자 로 요구하는 것으로 알려져 있다[44]. 이들 연구에서는 효소의 3 차원 구조에 기반하여 보조인자인 $\mathrm{NADPH}$ 와 근접하게 상호작 용하는 아미노산 잔기들을 면밀히 검토하여 $\mathrm{NADPH}$ 의 인산염 과 상호작용하는 잔기들을 찾아 돌연변이를 유도하여 $\mathrm{NADPH}$ 의존도가 낮은 돌연변이를 스크리닝한 것으로 알려져 있다[43]. $\mathrm{NADPH}$ 의 인산염 결합 부위의 잔기들의 돌연변이 S208D, S208E, Q210N, Q210S, K326H, K326N, K349R은 NADH에 대한 활성이 증가된 것으로 보고되어 있다[43]. 더 나아가 이 돌연변이들을 조합하여 야생형 대비 $\mathrm{NADH}$ 에 대한 활성을 2,600 배 이상 개선시킨 것으로 보고하고 있다[43]. 또한 보조인 자 분자에 직/간접적으로 상호작용하는 잔기들의 돌연변이를 추 가로 유발하여 L55R, S186P, T187L, V253Y, F284Q, D341C, $\mathrm{W} 490 \mathrm{Y}$ 의 변이가 $\mathrm{NADH}$ 에 대한 활성을 향상시킨 것으로도 알 려져 있다[43]. 또한, 이들을 조합하여 만든 변이체 중 S186P/ $\mathrm{S} 208 \mathrm{E} / \mathrm{K} 326 \mathrm{H}$ 와 $\mathrm{S} 186 \mathrm{P} / \mathrm{S} 208 \mathrm{E} / \mathrm{K} 326 \mathrm{H} / \mathrm{K} 349 \mathrm{R}$ 은 각각 $\mathrm{NADH}$ 에 대한 활성이 야생형 효소 대비 1,920 배 및 4,170 배 향상 된 것 으로 보고하고 있다[43]. 이들 연구는 특정 잔기의 돌연변이를 통해 $\mathrm{NADH}$ 의 수용비율을 높이긴 했지만 $\mathrm{BVMO}$ 의 보조인자 특이성을 완전히 전환한 것은 아닌 것으로 보고되어 있다[43].

\section{BVMO 효소의 전망}

$\mathrm{BVMO}$ 는 산업용 $\mathrm{BV}$ 산화 반응을 위한 주요 효소로써, $\mathrm{PE}$ 분 해 과정에서 주요한 효소로써 그 역할이 크게 기대되고 있다. 특히, $\mathrm{PE}$ 분해에 있어서 다양한 산화/환원 효소들의 작용으로 $\mathrm{PE}$ 구조에 carbonyl group이 형성된 뒤, 이들의 추가 분해에 반드시 $\mathrm{BVMO}$ 에 의한 $\mathrm{BV}$ 산화 과정이 필요한 실정이다. 하지 만, 이와 같은 $\mathrm{BVMO}$ 의 반응에는 앞서 언급된 $\mathrm{NADPH}$ 및 
$\mathrm{NADH}$ 보조인자가 제공되어야 한다. $\mathrm{PE}$ 와 같은 고분자 분해에 있어서는 BVMO 효소가 세포 밖으로 분비되거나 세포 표면에 서 외부 환경으로 노출되어야 할 것으로 전망되고 있다. 이와 같은 환경에서 보조인자의 재순환이 용이하지 않을 경우, $\mathrm{BVMO}$ 의 지속적인 활성을 기대하기는 어려울 것으로 예상된다. $\mathrm{BVMO}$ 를 이용한 화학공정에서도 이와 같은 문제는 공통된 것 으로 일부 보조인자의 재순환을 위한 연구가 시도된 바 있다 [42,45-47]. 즉, BVMO 반응에서 산화된 보조인자를 다른 효소 를 이용하여 환원시키는 전략이다. 이는 $\mathrm{NADP}^{+}$의존형 alcohol dehydrogenase를 이용하여 기질로써 endo-bicycloheptane-2-ol을 산화시키는 과정에서 $\mathrm{NADP}^{+}(\mathrm{BVMO}$ 반응에서 로 산화된 보조 인자)를 다시 환원 시킨 것으로 보고되어 있다[48]. 이와 같은 전략이 보조인자의 완전한 산화/환원 조절에 성공한 것은 아니 지만 앞으로 $\mathrm{BVMO}$ 의 산업적 이용에 있어서 더 나은 보조인 자 산화/환원 시스템을 갖추는 것 또한 $\mathrm{BVMO}$ 효소의 안정성 과 활성을 높이려는 노력과 함께 중요하게 고려되어야 함을 보 여주고 있다.

\section{초 록}

폴리에틸렌은 농업용 필름으로 널리 사용되고 있지만, 이를 친 환경적으로 분해하기 위한 기술은 부족한 상황이다. 이에 최근 폴리에틸렌 분해를 위한 친환경 기술 개발에 대한 관심이 높아 지고 있다. 폴레에틸렌의 생물학적 분해에는 몇가지 산화 단계 가 필요할 것이라고 예상된다. 먼저, 폴리에틸렌 사슬에 2차 알 코올이 형성되고, 알코올은 카르보닐기로 산화된다. 이후 과정 에서 카르보닐기는 Baeyer-Villiger monooxygenase (BVMO)에 의해 에스터로 전환되고, 이 에스터는 마지막 단계에서 lipase 와 esterase에 의해 절단될 것으로 예상된다. 본 연구에서는 폴 리에틸렌 분해 과정에 관여하는 중요한 효소 중 하나인 $\mathrm{BVMO}$ 의 반응 메커니즘, 분류, 효소공학 측면에서 리뷰하였다. 또한 $\mathrm{BVMO}$ 를 사용한 폴리에틸렌 분해 분야의 향후 연구전망도 간 략히 덧붙였다.

Keywords 메커니즘 · 폴리에틸렌 · 효소공학 · Baeyer-Villiger monooxygenases

감사의 글 This study was supported by Rural Development Administration, Republic of Korea through the "Cooperative Research Program for Agricultural Science \& Technology Development (Project No. PJ01492601)"

\section{References}

1. Ghatge S, Yang Y, Ahn J-H, Hur H-G (2020) Biodegradation of polyethylene: a brief review. Appl Biol Chem 63: 1-14. doi: 10.1186/ s13765-020-00511-3

2. Geyer R, Jambeck JR, Law KL (2017) Production, use, and fate of all plastics ever made. Sci Adv 3: e1700782. doi: 10.1126/sciadv. 1700782

3. Jambeck JR, Geyer R, Wilcox C, Siegler TR, Perryman M, Andrady A, Narayan R, Law KL (2015) Plastic waste inputs from land into the ocean. Science 347: 768-771. doi: 10.1126/science.1260352

4. Danso D, Chow J, Streit WR (2019) Plastics: environmental and biotechnological perspectives on microbial degradation. Appl Microbiol
Biotechnol 85: e01095-01019. doi: 10.1128/AEM.01095-19

5. Restrepo-Flórez J-M, Bassi A, Thompson MR (2014) Microbial degradation and deterioration of polyethylene-A review. Int Biodeter Biodegr 88: 83-90. doi: 10.1016/j.ibiod.2013.12.014

6. Hadad D, Geresh S, Sivan A (2005) Biodegradation of polyethylene by the thermophilic bacterium Brevibacillus borstelensis. J Appl Microbiol 98: 1093-1100. doi: 10.1111/j.1365-2672.2005.02553.x

7. Yamada-Onodera K, Mukumoto H, Katsuyaya Y, Saiganji A, Tani Y (2001) Degradation of polyethylene by a fungus, Penicillium simplicissimum YK. Polym Degrad Stab 72: 323-327. doi: 10.1016/S0141-3910(01) 00027-1

8. Tribedi P, Sil AK (2013) Low-density polyethylene degradation by Pseudomonas sp. AKS2 biofilm. Environ Sci Pollut Res 20: 4146-4153. doi: 10.1007/s11356-012-1378-y

9. Otake Y, Kobayashi T, Asabe H, Murakami N, Ono K (1995) Biodegradation of low-density polyethylene, polystyrene, polyvinyl chloride, and urea formaldehyde resin buried under soil for over 32 years. J Appl Polym Sci 56: 1789-1796. doi: 10.1002/app.1995. 070561309

10. Lee H-S, Hwang I-S, Park S-W, Choi G-H, Ryu S-H (2020) Identification of reduced plant uptake and reduction effects of azoxystrobin, procymidone and tricyclazole by biochars and quicklime. J Appl Biol Chem 63: 275-282. doi: 10.3839/jabc.2020.037

11. Lee S-H, Kwak S-Y, Hwang J-I, Kim H-J, Kim T-H, Kim J-E (2019) Correlation between physicochemical properties and biological half-life of triazole fungicides in perilla leaf. J Appl Biol Chem 62: 407-415. doi: $10.3839 /$ jabc. 2019.056

12. Kim S-H, Kim J-A, Im M-H (2020) Residual characteristics of pesticide in banana from international pesticide residue monitoring data. J Appl Biol Chem 63: 9-22. doi: 10.3839/jabc.2020.002

13. Hadad D, Geresh S, Sivan A (2005) Biodegradation of polyethylene by the thermophilic bacterium Brevibacillus borstelensis. J Appl Microbiol 98: 1093-1100. doi: 10.1111/j.1365 2672.2005.02553.x

14. Singh B, Sharma N (2008) Mechanistic implications of plastic degradation. Polym Degrad Stab 93: 561-584. doi: 10.1016/j.polymdegradstab. 2007.11.008

15. Whyte LG, Hawari J, Zhou E, Bourbonnière L, Inniss WE, Greer CW (1998) Biodegradation of variable-chain-length alkanes at low temperatures by a psychrotrophic Rhodococcus sp. Appl Environ Microbiol 64: 2578-2584. doi: 10.1128/AEM.64.7.2578-2584.1998

16. Van Beilen JB, Li Z, Duetz WA, Smits TH, Witholt B (2003) Diversity of alkane hydroxylase systems in the environment. Oil Gas Sci Technol 58: 427-440. doi: 10.2516/ogst:2003026

17. Sen SK, Raut S (2015) Microbial degradation of low density polyethylene (LDPE): A review. J Environ Chem Eng 3: 462-473. doi: 10.1016/j.jece.2015.01.003

18. Pathak VM, Navneet (2017) Review on the current status of polymer degradation: a microbial approach. Bioresour Bioprocess 4: 1-31. doi: 10.1186/s40643-017-0145-9

19. Kirschner A, Altenbuchner J, Bornscheuer UT (2007) Design of a secondary alcohol degradation pathway from Pseudomonas fluorescens DSM 50106 in an engineered Escherichia coli. Appl Microbiol Biotechnol 75: 1095-1101. doi: 10.1007/s00253-007-0902-3

20. Leisch H, Morley K, Lau PC (2011) Baeyer-Villiger monooxygenases: more than just green chemistry. Chem Rev 111: 4165-4222. doi: $10.1021 / \mathrm{cr} 1003437$

21. Chaiyen P, Fraaije MW, Mattevi A (2012) The enigmatic reaction of flavins with oxygen. Trends Biochem Sci 37: 373-380. doi: 10.1016/ j.tibs.2012.06.005

22. Palfey BA, McDonald CA (2010) Control of catalysis in flavindependent monooxygenases. Arch Biochem Biophys 493: 26-36. doi: 10.1016/j.abb.2009.11.028

23. Kamerbeek NM, Fraaije MW, Janssen DB (2004) Identifying determinants of NADPH specificity in Baeyer-Villiger monooxygenases. Eur J Biochem 271: 2107-2116. doi: 10.1111/j.1432-1033.2004.04126.x 
24. Fürst MJ, Gran-Scheuch A, Aalbers FS, Fraaije MW (2019) BaeyerVilliger monooxygenases: tunable oxidative biocatalysts. ACS Catal 9: 11207-11241. doi: 10.1021/acscatal.9b03396

25. Franceschini S, van Beek HL, Pennetta A, Martinoli C, Fraaije MW, Mattevi A (2012) Exploring the structural basis of substrate preferences in Baeyer-Villiger monooxygenases: insight from steroid monooxygenase. J Biol Chem 287: 22626-22634. doi: 10.1074/jbc.M112.372177

26. Schmidt S, Bornscheuer UT (2020) Baeyer-Villiger monooxygenases: From protein engineering to biocatalytic applications. In: The Enzymes, vol 47. Elsevier, pp 231-281. doi: 10.1016/bs.enz.2020.05.007

27. Malito E, Alfieri A, Fraaije MW, Mattevi A (2004) Crystal structure of a Baeyer-Villiger monooxygenase. Proc Natl Acad Sci USA 101: 1315713162. doi: 10.1073/pnas.0404538101

28. Orru R, Dudek HM, Martinoli C, Pazmiño DET, Royant A, Weik M, Fraaije MW, Mattevi A (2011) Snapshots of enzymatic Baeyer-Villiger catalysis: oxygen activation and intermediate stabilization. J Biol Chem 286: 29284-29291. doi: 10.1074/jbc.M111.255075

29. Mirza IA, Yachnin BJ, Wang S, Grosse S, Bergeron H, Imura A, Iwaki H, Hasegawa Y, Lau PC, Berghuis AM (2009) Crystal structures of cyclohexanone monooxygenase reveal complex domain movements and a sliding cofactor. J Am Chem Soc 131: 8848-8854. doi: 10.1021/ ja9010578

30. Riebel A, Dudek H, De Gonzalo G, Stepniak P, Rychlewski L, Fraaije M (2012) Expanding the set of rhodococcal Baeyer-Villiger monooxygenases by high-throughput cloning, expression and substrate screening. Appl Microbiol Biotechnol 95: 1479-1489. doi: 10.1007/s00253-011-3823-0

31. Ferroni FM, Tolmie C, Smit MS, Opperman DJ (2016) Structural and catalytic characterization of a fungal Baeyer-Villiger monooxygenase. PLoS One 11: e0160186. doi: 10.1371/journal.pone.0160186

32. Huijbers MM, Montersino S, Westphal AH, Tischler D, van Berkel WJ (2014) Flavin dependent monooxygenases. Arch Biochem Biophys 544: 2-17. doi: 10.1016/j.abb.2013.12.005

33. Van Berkel W, Kamerbeek N, Fraaije M (2006) Flavoprotein monooxygenases, a diverse class of oxidative biocatalysts. J Biotechnol 124: 670-689. doi: 10.1016/j.jbiotec.2006.03.044

34. Willetts A (2019) Characterised flavin-dependent two-component monooxygenases from the CAM plasmid of Pseudomonas putida ATCC 17453 (NCIMB 10007): ketolactonases by another name. Microorganisms 7: 1. doi: 10.3390/microorganisms7010001

35. Iwaki H, Grosse S, Bergeron H, Leisch H, Morley K, Hasegawa Y, Lau PC (2013) Camphor pathway redux: functional recombinant expression of 2, 5-and 3, 6-diketocamphane monooxygenases of Pseudomonas putida ATCC 17453 with their cognate flavin reductase catalyzing Baeyer-Villiger reactions. Appl Environ Microbiol 79: 3282-3293. doi: 10.1128/AEM.03958-12

36. Kadow M, Loschinski K, Saß S, Schmidt M, Bornscheuer UT (2012) Completing the series of BVMOs involved in camphor metabolism of Pseudomonas putida NCIMB 10007 by identification of the two missing genes, their functional expression in $E$. coli, and biochemical characterization. Appl Microbiol Biotechnol 96: 419-429. doi: 10.1007/ s00253-011-3859-1
37. Gibson M, Nur-e-alam M, Lipata F, Oliveira MA, Rohr J (2005) Characterization of kinetics and products of the Baeyer-Villiger oxygenase MtmOIV, the key enzyme of the biosynthetic pathway toward the natural product anticancer drug mithramycin from Streptomyces argillaceus. J Am Chem Soc 127: 17594-17595. doi: 10.1021/ja055750t

38. Tolmie C, Smit MS, Opperman DJ (2019) Native roles of BaeyerVilliger monooxygenases in the microbial metabolism of natural compounds. Nat Prod Rep 36: 326-353. doi: 10.1039/c8np00054a

39. Huang S, Tabudravu J, Elsayed SS, Travert J, Peace D, Tong MH, Kyeremeh K, Kelly SM, Trembleau L, Ebel R (2015) Discovery of a single monooxygenase that catalyzes carbamate formation and ring contraction in the biosynthesis of the legonmycins. Angew Chem Int Ed 54: 12697-12701. doi: 10.1002/anie.201502902

40. Schimming O, Challinor VL, Tobias NJ, Adihou H, Grün P, Pöschel L, Richter C, Schwalbe H, Bode HB (2015) Structure, biosynthesis, and occurrence of bacterial pyrrolizidine alkaloids. Angew Chem Int Ed 54: 12702-12705. doi: 10.1002/anie.201504877

41. Rix U, Remsing LL, Hoffmeister D, Bechthold A, Rohr J (2003) Urdamycin L: A novel metabolic shunt product that provides evidence for the role of the $u r d M$ gene in the urdamycin A biosynthetic pathway of Streptomyces fradiae Tu 2717. ChemBioChem 4: 109-111. doi: 10.1002/cbic. 200390002

42. Weckbecker A, Gröger H, Hummel W (2010) Regeneration of nicotinamide coenzymes: principles and applications for the synthesis of chiral compounds. In: Biosyst Eng. Springer, pp 195-242. doi: 10.1007/ 10_2009_55

43. Beier A, Bordewick S, Genz M, Schmidt S, Van Den Bergh T, Peters C, Joosten HJ, Bornscheuer UT (2016) Switch in cofactor specificity of a Baeyer-Villiger monooxygenase. ChemBioChem 17: 2312-2315. doi: 10.1002/cbic.201600484

44. Kelly DR, Knowles CJ, Mahdi JG, Taylor IN, Wright MA (1996) The enantioselective oxidation of sulfides to sulfoxides with Acinetobacter sp. NCIMB 9871, Pseudomonas sp. NCIMB 9872, Xanthobacter autotrophicus DSM 431 (NCIMB 10811) and the black yeast NV-2. Tetrahedron Asymmetry 7: 365-368. doi: 10.1016/0957-4166(96)000079

45. Dascier D, Kambourakis S, Hua L, Rozzell JD, Stewart JD (2014) Influence of cofactor regeneration strategies on preparative-scale, asymmetric carbonyl reductions by engineered Escherichia coli. Org Process Res Dev 18: 793-800. doi: 10.1021/op400312n

46. Hummel W, Gröger H (2014) Strategies for regeneration of nicotinamide coenzymes emphasizing self-sufficient closed-loop recycling systems. J Biotechnol 191: 22-31. doi: 10.1016/j.jbiotec.2014.07.449

47. Wang X, Saba T, Yiu HH, Howe RF, Anderson JA, Shi J (2017) Cofactor $\mathrm{NAD}(\mathrm{P}) \mathrm{H}$ regeneration inspired by heterogeneous pathways. Chem 2: 621-654. doi: 10.1016/j.chempr.2017.04.009

48. Willetts AJ, Knowles CJ, Levitt MS, Roberts SM, Sandey H, Shipston NF (1991) Biotransformation of endo-bicyclo[2.2.1]heptan-2-ols and endo-bicyclo[3.2.0]hept-2-en-6-ol into the corresponding lactones. J Chem Soc Perkin Trans I: 1608-1610. doi: 10.1039/P19910001608 